\title{
BMJ Open Risks of all-cause mortality and major kidney events in patients with new- onset primary open-angle glaucoma: a nationwide long-term cohort study in Taiwan
}

Chu-Lin Chou, ${ }^{1,2}$ Tsung-Cheng Hsieh, ${ }^{3}$ Jin-Shuen Chen, ${ }^{2}$ Te-Chao Fang ${ }^{1,4}$

To cite: Chou C-L, Hsieh T-C, Chen J-S, et al. Risks of allcause mortality and major kidney events in patients with new-onset primary open-angle glaucoma: a nationwide long-term cohort study in Taiwan. BMJ Open 2018;8:e021270. doi:10.1136/ bmjopen-2017-021270

- Prepublication history and additional material for this paper are available online. To view these files, please visit the journal online (http://dx.doi. org/10.1136/bmjopen-2017021270).

Received 21 December 2017 Revised 5 February 2018 Accepted 7 February 2018

Check for updates

${ }^{1}$ Division of Nephrology, Department of Internal Medicine, Taipei Medical University Hospital, Taipei Medical University, Taipei, Taiwan ${ }^{2}$ Division of Nephrology, Department of Internal Medicine, Tri-Service General Hospital, National Defense Medical Center, Taipei, Taiwan

${ }^{3}$ Institute of Medical Sciences,

Tzu Chi University, Hualien,

Taiwan

${ }^{4}$ Department of Internal Medicine, School of Medicine, College of Medicine, Taipei Medical University, Taipei, Taiwan

Correspondence to Professor Te-Chao Fang; fangtechao@gmail.com

\section{ABSTRACT}

Objective Cardiovascular risk factors are associated with primary open-angle glaucoma (POAG) in the general population. However, long-term mortality and major kidney events in patients with new-onset POAG remain unclear. Methods Using the Taiwan National Health Insurance Research Database between 1997 and 2011, 15185 patients with a new diagnosis of POAG were enrolled and propensity score matched (1:1) with 15185 patients without ocular disorders (WODs). All-cause mortality and major kidney events were analysed by a multivariate Cox proportional hazards regression model and a competing risk regression model.

Results The risk of all-cause mortality was significantly higher in patients with new-onset POAG than in those WODs (adjusted HR (aHR) 2.11, 95\% $\mathrm{Cl} 1.76$ to 2.54; $\mathrm{p}<0.001$ ). Patients with POAG had higher risks of acute renal failure (ARF) (competing risk aHR 2.58, 95\% Cl 1.88 to $3.55 ; p<0.001)$ and end-stage renal disease (ESRD) (competing risk aHR 4.84, 95\% $\mathrm{Cl} 3.02$ to $7.77 ; p<0.001$ ) than those WODs.

Conclusions Our data demonstrate that POAG is a risk of all-cause mortality, ARF and ESRD, thus needing to notice mortality and major kidney events in patients with newonset POAG.

\section{INTRODUCTION}

Primary open-angle glaucoma (POAG) is the most common form of glaucoma and is represented by acquired visual loss and optic nerve injury accompanied with elevated intraocular pressure (IOP) in the USA. ${ }^{1}$ This disease is typically asymptomatic until the occurrence of advanced visual loss. In addition to elevated IOP, some risk factors for POAG include age $>40$ years, African ancestry, a family history of POAG, myopia and the presence of cardiovascular risk factors, such as hypertension and diabetes. ${ }^{23}$ The mechanisms of optic nerve injury in POAG are unknown but could include damage to the lamina cribrosa ${ }^{4}$ and ischaemic changes due

\section{Strengths and limitations of this study}

- This study is the first to assess the outcomes of primary open-angle glaucoma (POAG) in a general population with respect to all-cause mortality and major kidney events.

> The participants were 15185 patients with a new diagnosis of POAG in a nationwide long-term cohort study.

- Through propensity score matching, this population-based cohort study adjusted for all potential risk factors to minimise the study errors. Major kidney events were analysed by a competing risk regression model to further confirm the hazard risk.

- Despite the large sample size, there may be other mediating factors beyond those explored in this analysis.

to insufficient ocular blood supply ${ }^{5}$ and retinal vessel lesions. ${ }^{78}$

Several studies have demonstrated the importance of evaluating cardiovascular risk factors for POAG. ${ }^{9}{ }^{10}$ Mroczkowska et al revealed that compared with controls, patients with POAG had increased nocturnal systemic blood pressure levels $(\mathrm{p}=0.01)$, peripheral arterial stiffness $(p=0.02)$ and carotid intimamedia thickness. ${ }^{9}$ An observational survey in 35 Italian academic centres evaluated cardiovascular risks in 2879 patients with POAG and age-matched controls. ${ }^{10}$ Patients with POAG had significantly higher systolic and diastolic blood pressures $(p=0.001)$ than the controls; in addition, the patients with POAG had a higher cardiovascular risk (OR 1.38, $\mathrm{p}=0.005) .{ }^{10}$ Therefore, POAG is associated with cardiovascular diseases.

The evaluation of cardiovascular risk factors is crucial in patients with POAG. ${ }^{9} 10$ However, the risk of all-cause mortality in patients with new-onset POAG remains 
Table 1 Clinical characteristics of POAG and WODs groups

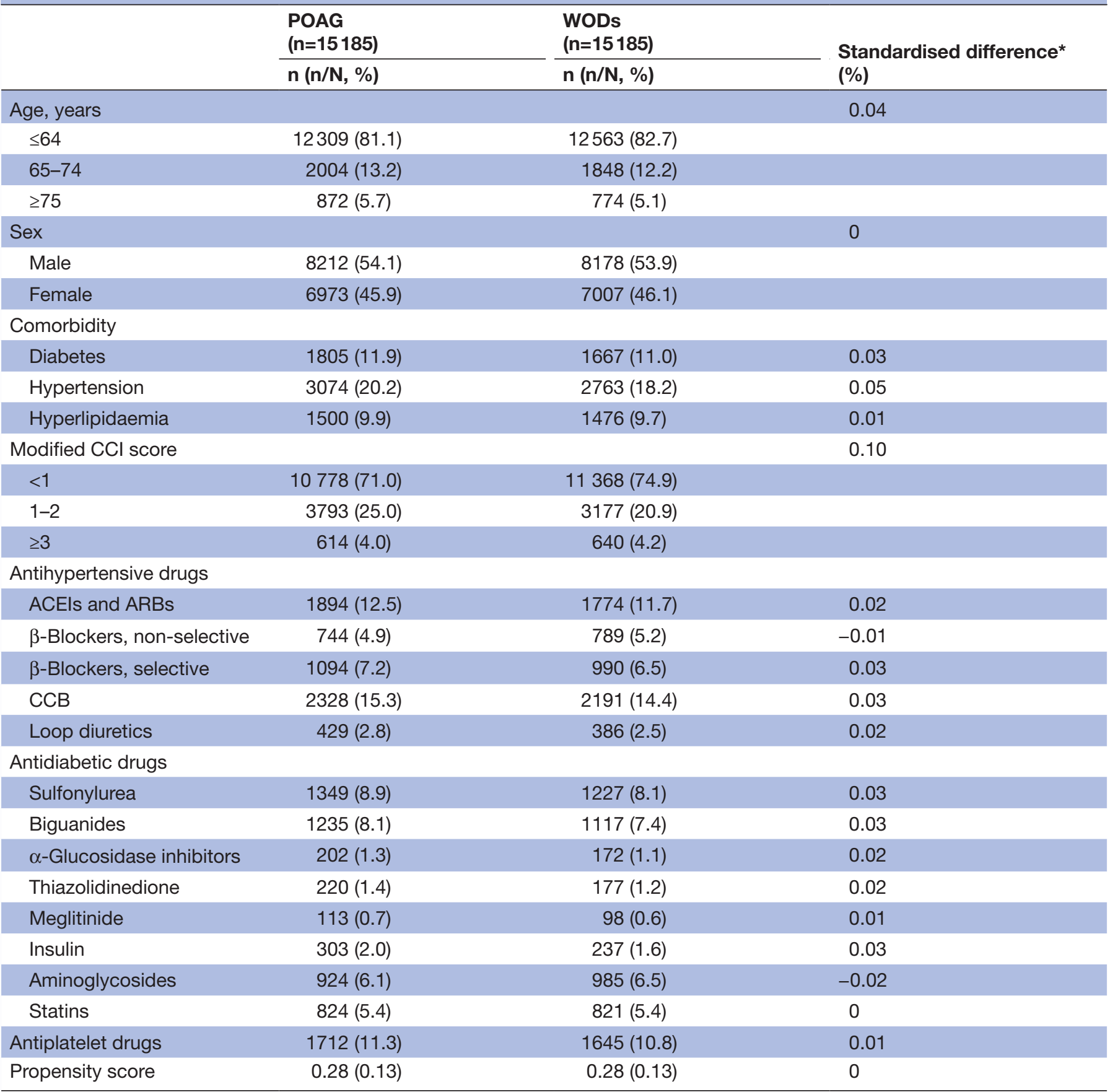

$\mathrm{n} / \mathrm{N}$, event numbers/total numbers.

*Standardised differences provide a measure of the difference between groups divided by the pooled SD. Standardised differences are less sensitive to sample size than traditional hypothesis tests. A value greater than $10 \%$ is interpreted as a significant difference between groups. ACEls, ACE inhibitors; ARBs, angiotensin II receptor blockers; CCB, calcium-channel blocker; CCI, Charlson Comorbidity Index; POAG, primary open-angle glaucoma; WODs, without ocular disorders.

unclear, and no studies have yet investigated the risk of major kidney events after POAG onset in the general population. Therefore, we used data from the Taiwan National Health Insurance Research Database (NHIRD) for the 1997-2011 period to examine the long-term outcomes of POAG in a general population with respect to all-cause mortality, acute renal failure (ARF) and end-stage renal disease (ESRD).

\section{MATERIALS AND METHODS}

\section{Data source}

This nationwide, observational, propensity scorematched cohort study used data from the Taiwan NHIRD. The Institutional Review Board waived the requirement of informed consent, and we confirmed that all experiments were performed in accordance with relevant guidelines and regulations. More than $99 \%$ of the citizens in 
(A)

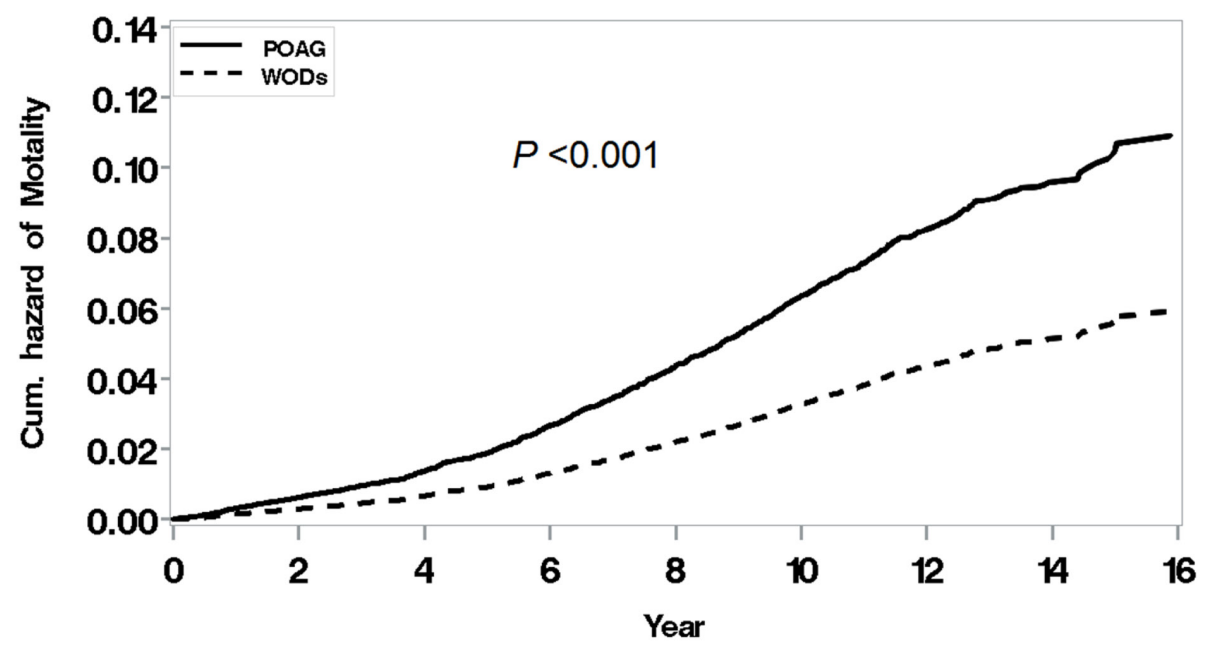

(B)

(C)
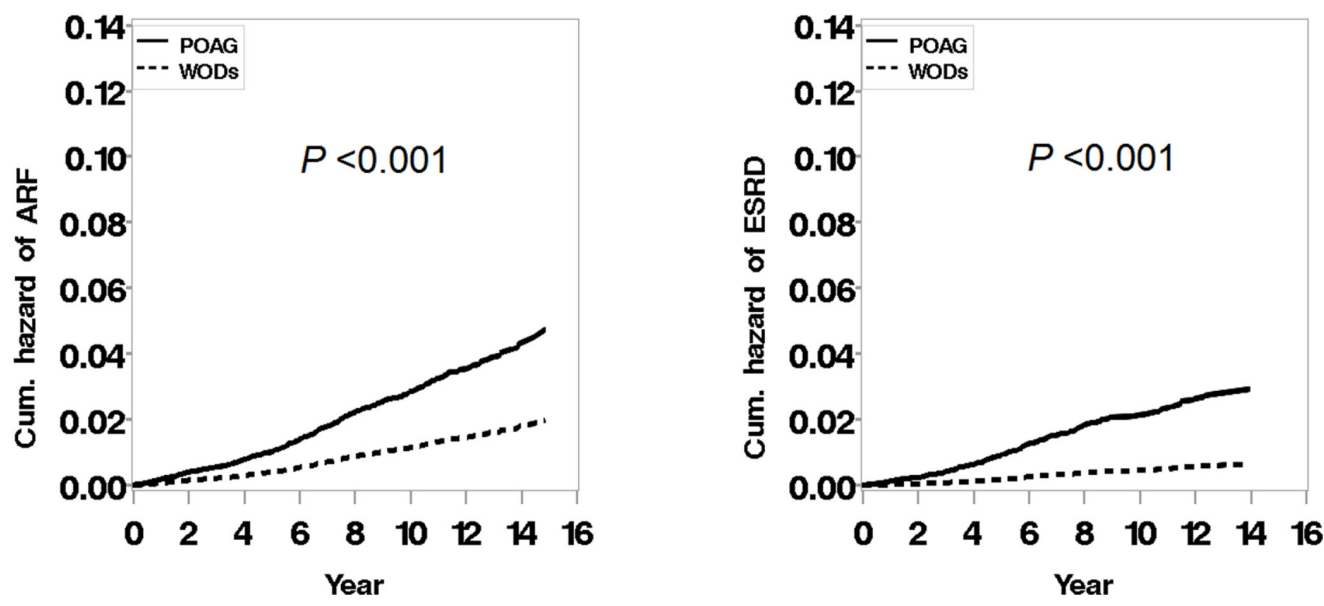

Figure 1 Cumulative (cum.) hazards in primary open-angle glaucoma (POAG) and without ocular disorders (WODs) groups in a cox proportional hazards regression model: (A) all-cause mortality; (B) acute renal failure (ARF) and (C) end-stage renal disease (ESRD).

Taiwan (approximately 23 million persons) are enrolled in the National Health Insurance programme, which has provided compulsory universal health insurance since 1995. ${ }^{11}$ The NHIRD contains clinical data for population-based longitudinal cohort studies in Taiwan. One of the highest quality databases worldwide, it has been widely used for longitudinal cohort studies ${ }^{12-19}$ including our previous reports. ${ }^{14-20}$

All data in the NHIRD are encrypted to protect patient privacy. The database provides a patient identification number; birth date; sex; names of medical institutions providing care; International Classification of Diseases, Ninth Revision, Clinical Modification (ICD-9-CM) diagnostic codes; drug prescriptions; procedure codes; healthcare costs; dates of admission and discharge; date of death; outpatient and inpatient claims data; and related information. All datasets can be interlinked through the unique identification number assigned to each patient.

\section{Study cohort and patient selection}

This study employed all of the registered information and items of the original claims of onemillion individuals between 1 January 1997 and 31 December 2011, from the NHIRD. Patients who developed ARF and ESRD prior to the occurrence of POAG were excluded. The remaining patients with available follow-up data were divided into two groups: patients with new-onset POAG and those without ocular disorders (WODs; online supplementary figure 1). Finally, patients and controls were enrolled and propensity score matched (1:1) by age, sex, diabetes, index date, hypertension, hyperlipidaemia, modified Charlson Comorbidity Index (CCI) score and baseline use of ACE inhibitors or angiotensin II receptor blockers, non-selective and selective $\beta$-blockers, calcium-channel blockers, loop diuretics, sulfonylurea, biguanides, $\alpha$-glucosidase inhibitors, thiazolidinedione, meglitinide, insulin, aminoglycosides, statins, and antiplatelet drugs. Because diabetes was considered a comorbidity, we excluded the diabetes item from the CCI 
Table 2 Incidences and risks of all-cause mortality and major kidney events in POAG and WODs groups

\begin{tabular}{|c|c|c|c|c|c|c|c|c|c|}
\hline & \multirow{2}{*}{$\begin{array}{l}\begin{array}{l}\text { POAG } \\
(n=15185)\end{array} \\
n / N \\
(\%)\end{array}$} & \multirow{2}{*}{$\begin{array}{l}\begin{array}{l}\text { WODs } \\
(\mathrm{n}=15185)\end{array} \\
\mathrm{n} / \mathrm{N} \\
(\%)\end{array}$} & \multirow[b]{2}{*}{$P$ values } & $\begin{array}{l}\text { POAG } \\
(n=15185)\end{array}$ & $\begin{array}{l}\text { WODs } \\
(n=15185)\end{array}$ & \multirow{2}{*}{$\begin{array}{l}\text { Multivariate Cox } \\
\text { regression† } \\
\text { aHR } \\
(95 \% \mathrm{Cl})\end{array}$} & \multirow[b]{2}{*}{$P$ values } & \multirow{2}{*}{$\begin{array}{l}\text { Competing risk† } \\
\text { aHR } \\
(95 \% \mathrm{Cl})\end{array}$} & \multirow[b]{2}{*}{$P$ values } \\
\hline & & & & \multicolumn{2}{|c|}{$\begin{array}{l}\text { Cumulative incidence rate, } \\
1000 \text { person-years ( } 95 \% \text { IR) }\end{array}$} & & & & \\
\hline $\begin{array}{l}\text { All-cause } \\
\text { Mortality }\end{array}$ & $\begin{array}{l}734 \\
(4.8)\end{array}$ & $\begin{array}{l}345 \\
(2.3)\end{array}$ & $<0.001^{*}$ & $\begin{array}{l}6.1 \\
(5.5-6.7)\end{array}$ & $\begin{array}{l}2.9 \\
(2.4-3.3)\end{array}$ & $\begin{array}{l}2.11 \\
(1.76 \text { to } 2.54)\end{array}$ & $<0.001^{*}$ & - & - \\
\hline ARF & $\begin{array}{l}287 \\
(1.9)\end{array}$ & $\begin{array}{l}111 \\
(0.7)\end{array}$ & $<0.001^{*}$ & $\begin{array}{l}2.4 \\
(2.0-2.8)\end{array}$ & $\begin{array}{l}0.9 \\
(0.7-1.2)\end{array}$ & $\begin{array}{l}2.65 \\
(1.93 \text { to } 3.63)\end{array}$ & $<0.001^{*}$ & $\begin{array}{l}2.58 \\
(1.88 \text { to } 3.55)\end{array}$ & $<0.001^{*}$ \\
\hline
\end{tabular}

$\mathrm{n} / \mathrm{N}$, event numbers/total numbers.

${ }^{*}$ Denotes $\mathrm{p}<0.005$ and was considered statistically significant.

†Adjusted for all covariates after propensity score matching (table 1).

aHR, adjusted HR; ARF, acute renal failure; ESRD, end-stage renal disease; IR, incidence rate; POAG, primary open-angle glaucoma; WODs, without ocular disorders.

score to avoid repeated calculation, and the derived score was defined as the modified CCI score. The index date was defined as the onset date of POAG. The study follow-up period started from the onset date of POAG. We assigned a date for the control patients who did not experience a POAG event, as a pseudo-POAG event, which matched to the index date of their corresponding case patients (referred to as the index date). This tactic method minimised the length time bias in this cohort study because both groups had the same time frame.

\section{Outcomes of mortality and kidney events}

For analyses of the study endpoints, namely all-cause mortality, ARF and ESRD, we censored patients either at their time of death or at the end of follow-up on 31 December 2011.

\section{ICD-9-CM codes}

The ICD-9-CM codes and drug use of patients are interlinked by patient identification numbers in the NHIRD. The ICD-9-CM codes for POAG and ARF are 365.XX and 584.X, respectively. Patients with dialysis are defined as those with catastrophic illness registration cards for ESRD (ICD-9-CM: 585.X) and who received haemodialysis (HD) or peritoneal dialysis for $>3$ months of renal replacement therapy. The ICD-9-CM codes for the comorbidities are as follows: diabetes mellitus (250.X), hypertension (401.X405.X, 437.2 and 362.11), hyperlipidaemia (272.X) and gout (274.X). We modified the CCI score to exclude the diabetes item from the calculation to avoid repeated calculation for the aforementioned comorbidities. Online supplementary table 1 lists the ICD-9-CM codes. The definition and measurement of the modified CCI score are based on the procedures proposed by Charlson $e t a 2^{21}$ The CCI score is commonly used to analyse the effects of comorbidities on mortality. ${ }^{22}$

\section{Statistical analysis}

Through propensity score matching, the two groups were balanced with respect to known confounders to ensure comparability during analyses. ${ }^{21}$ We adjusted for potential confounding variables based on clinical relevance, namely age, sex, index date, diabetes, hypertension, hyperlipidaemia, modified CCI score and baseline use of ACE inhibitors or angiotensin II receptor blockers, non-selective and selective $\beta$-blockers, calcium-channel blockers, loop diuretics, sulfonylurea, biguanides, $\alpha$-glucosidase inhibitors, thiazolidinedione, meglitinide, insulin, aminoglycosides, statins, and antiplatelet drugs. Age was considered a categorical variable ( $\leq 64,65-74$ and $\geq 75$ years). Patient baseline characteristics were compared using standardised differences that reflect the mean difference as a percentage of the SD, as described by Mamdani et $a l^{23}$ The drawback of traditional statistical tests, such as $\chi^{2}$ (for dichotomous variables) or $\mathrm{t}$ (for continuous variables) tests, is that the significance levels are sensitive to sample size, and these tests are not highly meaningful in studies with large sample sizes. A standardised difference measure is less sensitive to sample size than these traditional hypothesis tests and estimates the relative magnitude of differences. Standardised difference of $>10 \%$ indicates important imbalance and is interpreted as significant difference in the mean of a covariate between treatment groups. ${ }^{23}$ Multivariate Cox proportional hazards regression models were used to assess the adjusted HRs (aHRs) and 95\% CIs of all-cause mortality, ARF and ESRD. Because patients with HD have a high all-cause mortality rate, a competing risk regression analysis was performed to assess and demonstrate the reliability of ARF and ESRD outcomes. The frameworks of the competing risk models were constructed as described previously by Lau $e t a l^{24}$ SAS statistical software (SAS System for Windows, V.9.3; SAS Institute) was used for statistical analysis. All statistical tests were two sided, and $\mathrm{p}<0.005$ was considered statistically significant for the all-cause mortality and major kidney events.

\section{RESULTS}

\section{Patient characteristics}

In our study, 21979 patients with new-onset POAG were identified from the NHIRD between January 1997 and 
Table 3 All-cause mortality in POAG and WODs groups

\section{Cox regression aHR}

$(95 \% \mathrm{Cl})$

$P$ values

All-cause mortality $\quad 2.11(1.76$ to 2.54$)<0.001^{*}$
Age, years

$\begin{array}{lll}\leq 64 & \text { Reference } & \\ 65-74 & 4.04(3.18 \text { to } 5.13) & <0.001^{*} \\ \geq 75 & 11.64(9.36 \text { to } 14.47) & <0.001^{*}\end{array}$

Sex

\begin{tabular}{|c|c|c|}
\hline Female & Reference & \\
\hline Male & 1.31 (1.08 to 1.58$)$ & $<0.001^{*}$ \\
\hline \multicolumn{3}{|l|}{ Comorbidity } \\
\hline Diabetes & $1.06(0.74$ to 1.53$)$ & 0.640 \\
\hline Hypertension & 0.99 (0.77 to 1.27$)$ & 0.882 \\
\hline Hyperlipidaemia & 0.75 (0.53 to 1.06$)$ & 0.018 \\
\hline \multicolumn{3}{|l|}{ Modified CCI score } \\
\hline$<1$ & Reference & \\
\hline $1-2$ & 1.73 (1.38 to 2.16$)$ & $<0.001^{*}$ \\
\hline$\geq 3$ & 3.02 (2.21 to 4.11$)$ & $<0.001^{*}$ \\
\hline \multicolumn{3}{|l|}{ Antihypertensive drugs } \\
\hline ACEls and ARBs & 1.04 (0.82 to 1.32$)$ & 0.651 \\
\hline $\begin{array}{l}\beta \text {-Blockers, non- } \\
\text { selective }\end{array}$ & $1.10(0.79$ to 1.51$)$ & 0.428 \\
\hline$\beta$-Blockers, selective & $0.95(0.71$ to 1.26$)$ & 0.605 \\
\hline CCB & 1.31 (1.04 to 1.65$)$ & $0.001^{*}$ \\
\hline Loop diuretics & 1.49 (1.09 to 2.04$)$ & $<0.001^{*}$ \\
\hline \multicolumn{3}{|l|}{ Antidiabetic drugs } \\
\hline Sulfonylurea & 1.51 (1.05 to 2.15$)$ & $0.001^{*}$ \\
\hline Biguanides & $1.04(0.74$ to 1.47$)$ & 0.734 \\
\hline$\alpha$-Glucosidase inhibitors & 1.33 (0.70 to 2.50$)$ & 0.213 \\
\hline Thiazolidinedione & $0.56(0.25$ to 1.29$)$ & 0.051 \\
\hline Meglitinide & 1.42 (0.69 to 2.93$)$ & 0.177 \\
\hline Insulin & 1.74 (1.17 to 2.58$)$ & $0.001^{*}$ \\
\hline Aminoglycosides & 1.33 (1.04 to 1.70$)$ & $0.001^{*}$ \\
\hline Statins & $1.19(0.80$ to 1.77$)$ & 0.229 \\
\hline Antiplatelet drugs & $0.95(0.76$ to 1.18$)$ & 0.503 \\
\hline
\end{tabular}

Adjusted for all covariates after propensity score matching (table 1).

*Denotes $p<0.005$ and was considered statistically significant. ACEls, ACE inhibitors; aHR, adjusted HR; ARBs, angiotensin II receptor blockers; $\mathrm{CCB}$, calcium-channel blocker; $\mathrm{CCI}$, Charlson Comorbidity Index; POAG, primary open-angle glaucoma; WODs, without ocular disorders.

December 2011 after the exclusion of patients with ARF $(\mathrm{n}=115)$ and ESRD ( $\mathrm{n}=111$; online supplementary figure $1)$. Furthermore, patients and controls were propensity score matched (1:1) by age, sex, index date, and all covariates and divided into POAG $(\mathrm{n}=15185)$ and WODs $(\mathrm{n}=15[185)$ groups. The two groups did not exhibit significant differences in age, sex, diabetes, hypertension, hyperlipidaemia, modified CCI score and baseline use of antihypertensive and antidiabetic drugs, aminoglycosides, statins, and antiplatelet drugs (table 1).

Comparison of POAG and WODs group in relation to all-cause mortality and major kidney events

Table 2 and figure 1 present the incidence and risks of all-cause mortality and major kidney events in the POAG and WODs groups. The POAG group had a higher all-cause mortality rate than the WODs group during the follow-up period. Similarly, the POAG group had higher incidences and risks of ARF and ESRD than the WODs group.

Table 3 presents the multivariate Cox proportional hazards regression analysis results of all-cause mortality. All covariates were adjusted for after propensity score matching (table 1), and the POAG group had a higher all-cause mortality rate than the WODs group. Older age ( $\geq 65$ years) and male sex were associated with a higher risk of all-cause mortality in the POAG group than in the WODs group. A modified CCI score of $\geq 1$ and the baseline use of drugs, such as calcium-channel blockers, loop diuretics, sulfonylurea, insulin and aminoglycosides were associated with a higher all-cause mortality rate in the POAG group than in the WODs group.

Table 4 presents the results of multivariate Cox proportional hazards and competing risk regression models for ARF and ESRD. The POAG group had a higher risk of ARF than the WODs group. Older age ( $\geq 65$ years); a modified CCI score of $\geq 1$ and baseline use of ACE inhibitors and angiotensin II receptor blockers, calcium-channel blockers, loop diuretics, and insulin were associated with a higher risk of ARF in the POAG group than in the WODs group. Similarly, the POAG group had a significantly higher risk of ESRD than the WODs group. In addition, diabetes, modified CCI score $\geq 3$, and baseline use of loop diuretics and insulin were associated with a higher risk of ESRD in the POAG group than in the WODs group.

\section{DISCUSSION}

The present study evaluated the long-term all-cause mortality and was the first to examine the risk of major kidney events in patients with new-onset POAG. The major findings of our study were as follows: patients with new-onset POAG had (1) a significantly higher incidence and risk of all-cause mortality and (2) significantly higher incidences and risks of ARF and ESRD than those WODs.

In this nationwide, population-based longitudinal cohort, the analysis of long-term survival in both groups revealed that new-onset POAG is associated with a risk of all-cause mortality, with a higher association for individuals of older age and the male sex. However, studies have yet to clearly clarify the risk of all-cause mortality in patients with new-onset POAG. ${ }^{25-28}$ For example, a meta-analysis in 2009 revealed that although the higher risk of all-cause mortality in the final pooled analysis 


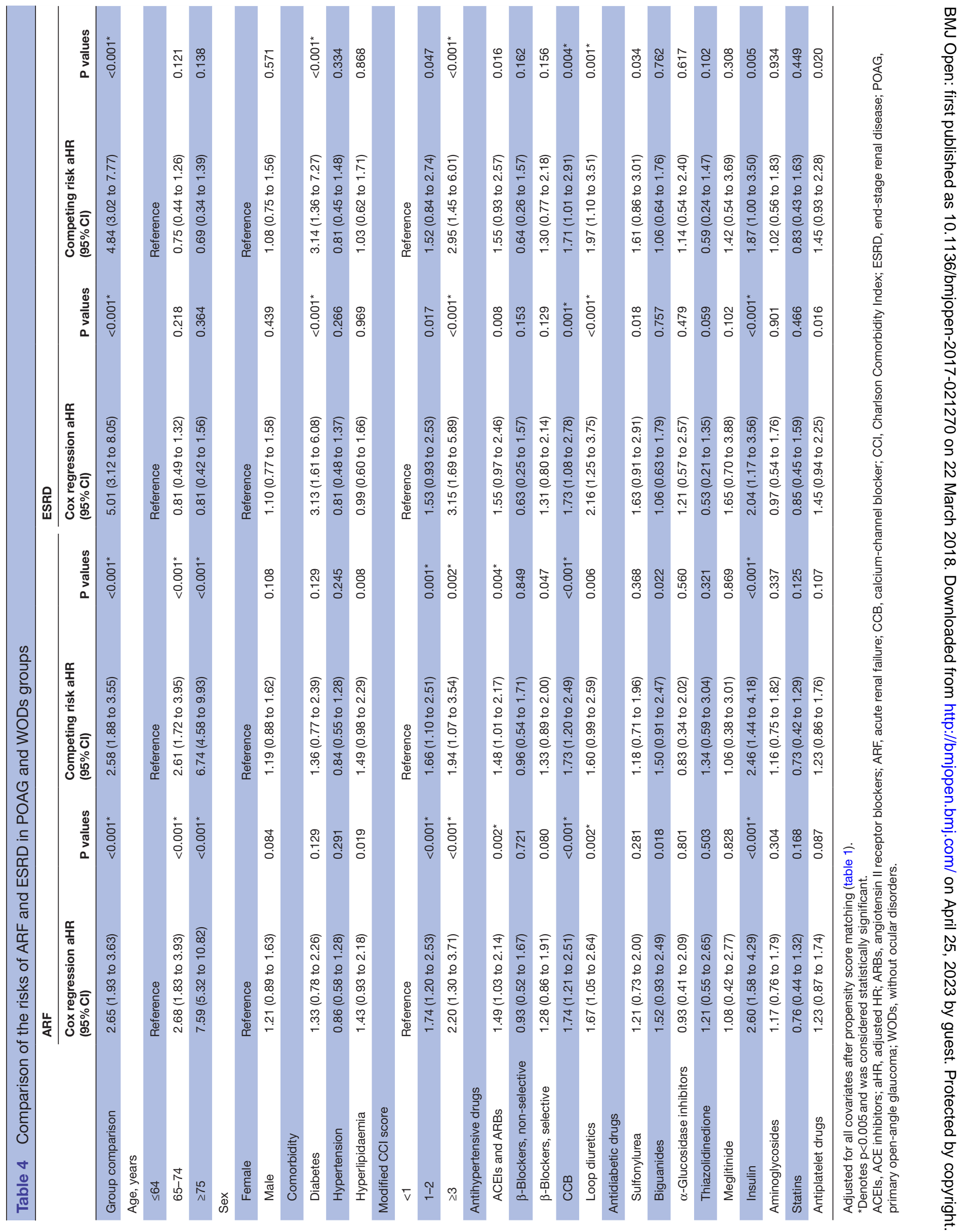


was marginally non-significant in patients with POAG (relative risk (RR) 1.13, 95\% CI 0.97 to 1.31 ), a pooled analysis demonstrated a significant association between POAG and cardiovascular mortality in four of the nine studies included (RR $1.20,95 \%$ CI 1.00 to $1.43 ; \mathrm{p}=0.05$ ) ${ }^{25}$ However, that review was limited to few studies and did not exclude the possibility that POAG is a part of the systemic vascular diseases that directly cause premature death. By contrast, Tarkkanen and Kivelä showed that the mortality of patients with POAG is associated with older age (median: 81.8 years) and male sex. ${ }^{26}$ Moreover, in a study of 741 patients with POAG between 1996 and 2005, Hewitt $e$ al reported that the mean age at death of patients with POAG was $83.8 \pm 7.8$ years and was significantly associated with older age $(\mathrm{p}<0.0001 ; \mathrm{z}=-13.25)$. Further adjustment for age at death and male sex demonstrated that the primary cause of death was associated with ischaemic heart disease in patients with POAG (OR 1.30, 95\% CI 1.08 to $1.56 ; \mathrm{p}=0.006) .{ }^{27}$ This finding is consistent with the Blue Mountains Eye study by Lee $e t a l^{28}$ which demonstrated an increased risk of cardiovascular mortality in patients with POAG. The reasons for the inconsistency in the results on the association between mortality and POAG are unknown and may be because several studies ignore that POAG is a part of systemic vascular diseases, directly causes premature death and does not increase the risk of all-cause mortality.

Cardiovascular risk factors are associated with the risk of POAG..$^{29}$ A systemic review and meta-analysis revealed that diabetes mellitus, a risk factor for cardiovascular and all-cause mortality ${ }^{3031}$ are positively associated with POAG (OR $1.35,95 \%$ CI 1.06 to 1.74 ).$^{32}$ In addition, a meta-analysis demonstrated an association between hypertension and the risk of POAG. ${ }^{33}$ In the Gangnam Eye Study of 5021 individuals, Kim et al reported that old age, high baseline elevated IOP and high body mass index are significant risk factors for incident POAG in the Korean population, ${ }^{34}$ which is similar to the findings of Chiam et al in the Chinese population. ${ }^{35}$ Moreover, a recent systemic review revealed a positive association between smoking and POAG. ${ }^{36}$ Therefore, these studies support cardiovascular involvement in the pathogenesis of POAG in the general population.

A population-based retrospective cohort study of 3510 patients with POAG from 2001 to 2011 in Taiwan demonstrated a significant association between POAG and ischaemic heart disease (aHR 1.41, 95\% CI 1.16 to 1.72 ) ${ }^{37} \mathrm{In}$ addition, atherosclerotic events are risk factors for renal failure. ${ }^{38}$ Our results demonstrated that the POAG group had a higher risk of ARF and ESRD than the WODs group. Although the underlying mechanisms remain unclear, the atherosclerotic vascular processes in POAG may be involved in the progression of renal failure.

The present study had some strengths, such as large sample size and the use of a nationwide database and propensity score matching. This population-based cohort study adjusted for all potential risk factors to minimise the study errors. To ensure the reliability of ARF and ESRD outcomes, the frameworks of competing risk models were constructed on the basis of the method used by Lau et al in an epidemiological study. ${ }^{24}$ However, despite its strengths and novelty, the present study had some limitations. First, the Taiwan NHIRD protects the privacy of patients; therefore, we could not obtain information regarding the educational level, occupation, use of tobacco and alcohol, and family history of patients. Second, data on the causes of death were not available from the NHIRD; therefore, we could not compare the causes of death between the POAG and WODs groups.

\section{CONCLUSION}

In this nationwide long-term cohort study, the POAG group had substantially higher risks of all-cause mortality, ARF and ESRD than the propensity score-matched WODs group. Notably, this study was the first to demonstrate that patients with new-onset POAG are at an increased risk of major kidney events. Therefore, evaluating the risks of all-cause mortality and major kidney events in patients with new-onset POAG should be mandatory.

Acknowledgements The authors thank the Bureau of Health Promotion, Department of Health and National Health Research Institutes for providing access to the NHIRD. This study was based in part on the data from the NHIRD, which are provided by the National Health Insurance Administration and Department of Health and managed by the National Health Research Institutes. The interpretations and conclusions of this study do not represent those of the Bureau of NHI, Department of Health or National Health Research Institutes.

Contributors C-LC, T-CH and T-CF designed the research. C-LC, T-CH, J-SC and T-CF conducted the research. C-LC, T-CH and T-CF analysed data and performed the statistical analysis. C-LC and T-CF wrote and edited the manuscript. T-CF had the primary responsibility for the final content. All authors read and approved the final manuscript.

Funding This research received no specific grant from any funding agency in the public, commercial or not-for-profit sectors.

Competing interests None declared.

Patient consent Detail has been removed from this case description/these case descriptions to ensure anonymity. The editors and reviewers have seen the detailed information available and are satisfied that the information backs up the case the authors are making.

Ethics approval The Institutional Review Board of Taipei Medical University (TMU-JIRB No: N201510050) approved this study.

Provenance and peer review Not commissioned; externally peer reviewed.

Data sharing statement All data are in the public domain.

Open Access This is an Open Access article distributed in accordance with the Creative Commons Attribution Non Commercial (CC BY-NC 4.0) license, which permits others to distribute, remix, adapt, build upon this work non-commercially, and license their derivative works on different terms, provided the original work is properly cited and the use is non-commercial. See: http://creativecommons.org/ licenses/by-nc/4.0/

(C) Article author(s) (or their employer(s) unless otherwise stated in the text of the article) 2018. All rights reserved. No commercial use is permitted unless otherwise expressly granted.

\section{REFERENCES}

1. Van Buskirk EM, Cioffi GA. Glaucomatous optic neuropathy. Am J Ophthalmol 1992;113:447-52.

2. Kwon $\mathrm{YH}$, Fingert $\mathrm{JH}$, Kuehn $\mathrm{MH}$, et al. Primary open-angle glaucoma. N Engl J Med 2009;360:1113-24. 
3. Weinreb RN, Khaw PT. Primary open-angle glaucoma. Lancet 2004;363:1711-20.

4. Yan DB, Coloma FM, Metheetrairut A, et al. Deformation of the lamina cribrosa by elevated intraocular pressure. $\mathrm{Br} \mathrm{J}$ Ophthalmol 1994;78:643-8.

5. Flammer J, Orgül S, Costa VP, et al. The impact of ocular blood flow in glaucoma. Prog Retin Eye Res 2002;21:359-93.

6. Gherghel D, Orgül S, Gugleta K, et al. Relationship between ocular perfusion pressure and retrobulbar blood flow in patients with glaucoma with progressive damage. Am J Ophthalmol 2000;130:597-605.

7. Su WW, Cheng ST, Ho WJ, Ww S, Wj H, et al. Glaucoma is associated with peripheral vascular endothelial dysfunction. Ophthalmology 2008;115:1173-8.

8. Garhöfer $\mathrm{G}$, Zawinka $\mathrm{C}$, Resch $\mathrm{H}$, et al. Response of retinal vessel diameters to flicker stimulation in patients with early open angle glaucoma. J Glaucoma 2004;13:340-4.

9. Mroczkowska S, Benavente-Perez A, Negi A, et al. Primary open-angle glaucoma vs normal-tension glaucoma: the vascular perspective. JAMA Ophthalmol 2013;131:36-43.

10. Orzalesi N, Rossetti L, Omboni S, et al. Vascular risk factors in glaucoma: the results of a national survey. Graefes Arch Clin Exp Ophthalmol 2007:245:795-802.

11. Cheng TM. Taiwan's new national health insurance program: genesis and experience so far. Health Aff 2003;22:61-76.

12. Hwang DK, Chou YJ, Pu CY, Cy P, et al. Epidemiology of uveitis among the Chinese population in Taiwan: a population-based study. Ophthalmology 2012;119:2371-6.

13. Chung SD, Hu CC, Ho JD, $\mathrm{Cc} \mathrm{H}$, Jd H, et al. Open-angle glaucoma and the risk of erectile dysfunction: a population-based case-control study. Ophthalmology 2012;119:289-93.

14. Lin HF, Li YH, Wang CH, et al. Increased risk of cancer in chronic dialysis patients: a population-based cohort study in Taiwan. Nephrol Dial Transplant 2012;27:1585-90.

15. Hung TH, Chou CL, Fang TC. Impact of renal dysfunction in cirrhotic patients with bacterial infections other than spontaneous bacterial peritonitis. Hepatol Res 2014:44:863-70.

16. Chou CL, Hsieh TC, Wang CH, et al. Long-term outcomes of dialysis patients after coronary revascularization: a population-based cohort study in Taiwan. Arch Med Res 2014;45:188-94.

17. Kuo $\mathrm{CH}$, Hsieh $\mathrm{TC}$, Wang $\mathrm{CH}$, et al. Increased risks of mortality and atherosclerotic complications in incident hemodialysis patients subsequently with bone fractures: a nationwide case-matched cohort study. PLoS One 2015;10:e0121705.

18. Wang YC, Hsieh TC, Chou CL, et al. Risks of Adverse Events Following Coprescription of Statins and Calcium Channel Blockers: A Nationwide Population-Based Study. Medicine 2016;95:e2487.

19. Hsieh TC, Chou CL, Chen JS, et al. Risk of Mortality and of Atherosclerotic Events Among Patients Who Underwent Hemodialysis and Subsequently Developed Retinal Vascular Occlusion: A Taiwanese Retrospective Cohort Study. JAMA Ophthalmol 2016;134:196-203.

20. Chien LN, Chou CL, Chen HH, et al. Association between stroke risk and metformin use in hemodialysis patients with diabetes mellitus: a nested case-control study. J Am Heart Assoc 2017;6:e007611.
21. Charlson ME, Pompei P, Ales KL, et al. A new method of classifying prognostic comorbidity in longitudinal studies: development and validation. J Chronic Dis 1987;40:373-83.

22. Deyo RA, Cherkin DC, Ciol MA. Adapting a clinical comorbidity index for use with ICD-9-CM administrative databases. J Clin Epidemiol 1992;45:613-9.

23. Mamdani M, Sykora K, Li P, et al. Reader's guide to critical appraisal of cohort studies: 2. Assessing potential for confounding. BMJ 2005;330:960-2.

24. Lau B, Cole SR, Gange SJ. Competing risk regression models for epidemiologic data. Am J Epidemiol 2009;170:244-56.

25. Akbari M, Akbari S, Pasquale LR. The association of primary openangle glaucoma with mortality: a meta-analysis of observational studies. Arch Ophthalmol 2009;127:204-10.

26. Tarkkanen AH, Kivelä TT. Mortality in primary open-angle glaucoma and exfoliative glaucoma. Eur J Ophthalmol 2014;24:718-21.

27. Hewitt AW, Sanfilippo P, Ring MA, et al. Mortality in primary open-angle glaucoma: 'two cupped discs and a funeral'. Eye 2010;24:59-63.

28. Lee AJ, Wang JJ, Kifley A, et al. Open-angle glaucoma and cardiovascular mortality: the Blue Mountains Eye Study. Ophthalmology 2006;113:1069-76.

29. Tsai JC. Influencing ocular blood flow in glaucoma patients: the cardiovascular system and healthy lifestyle choices. Can J Ophthalmol 2008;43:347-50.

30. Wei M, Gaskill SP, Haffner SM, et al. Effects of diabetes and level of glycemia on all-cause and cardiovascular mortality. The San Antonio Heart Study. Diabetes Care 1998;21:1167-72.

31. Lotufo PA, Gaziano JM, Chae CU, et al. Diabetes and all-cause and coronary heart disease mortality among US male physicians. Arch Intern Med 2001;161:242-7.

32. Zhou M, Wang W, Huang W, et al. Diabetes mellitus as a risk factor for open-angle glaucoma: a systematic review and meta-analysis. PLoS One 2014;9:e102972.

33. Zhao D, Cho J, Kim MH, et al. The association of blood pressure and primary open-angle glaucoma: a meta-analysis. Am J Ophthalmol 2014;158:615-27.

34. Kim YK, Choi HJ, Jeoung JW, et al. Five-year incidence of primary open-angle glaucoma and rate of progression in health centerbased Korean population: the Gangnam Eye Study. PLoS One 2014;9:e114058.

35. Chiam N, Baskaran M, Li Z, et al. Social, health and ocular factors associated with primary open-angle glaucoma amongst Chinese Singaporeans. Clin Exp Ophthalmol 2018;46.

36. Jain V, Jain M, Abdull MM, et al. The association between cigarette smoking and primary open-angle glaucoma: a systematic review. Int Ophthalmol 2017;37:291-301.

37. Chen YY, Hu HY, Chu D, et al. Patients with Primary Open-Angle Glaucoma May Develop Ischemic Heart Disease More Often than Those without Glaucoma: An 11-Year Population-Based Cohort Study. PLoS One 2016;11:e0163210.

38. Abuelo JG. Diagnosing vascular causes of renal failure. Ann Intern Med 1995;123:601-14. 